\title{
FONTES DO DIREITO DO TRABALHO
}

\author{
Otavio Pinto e Silva \\ Professor Assistente do Departamento de Direito do Trabalho da \\ Faculdade de Direito da Universidade de São Paulo
}

\begin{abstract}
Resumo:
O presente estudo identifica as várias fontes de produção de normas jurídicas trabalhistas, demonstrando que o Direito do Trabalho é um ramo do Direito que se caracteriza pelo pluralismo.
\end{abstract}

Abstract:

This study identifies various sources of production of labor rules, demonstrating that labor law is a branch of law characterized by pluralism.

Unitermos: Fontes do Direito, Direito do Trabalho, Pluralismo.

"la conoscenza di un ordinamento giuridico (e anche di un particolare settore di questo ordinamento) comincia sempre dalla enumerazione delle sue fonti" Norberto Bobbio ${ }^{1}$

1. Conceitos: Fontes Materiais e Fontes Formais

"Fonte material": conjunto dos fenômenos sociais que contribuem para a formação da matéria do Direito, ou seja, os fatores ou elementos que determinam a substância das normas jurídicas e o conteúdo de todo um sistema jurídico. O homem ao buscar nos fatos sociais as bases para a construção de um ordenamento jurídico está sempre formulando decisões políticas, que nada mais são do que os frutos da correlação de forças existentes no meio em que vive. 35 .

1. Bobbio, Norberto. Teoria dell'Ordinamento Giuridico, Torino, G.Giappichclli Editorc, 1960, p. 
"Fonte formal": maneira pela qual o Direito se revela socialmente; os processos de manifestação do Direito, através dos quais um ordenamento jurídico adquire existência, atuando de maneira válida e eficaz dentro de um determinado contexto social. É preciso lembrar que um ordenamento jurídico não se limita a regular o comportamento dos indivíduos em sociedade, mas vai mais além, tratando, também, de fixar o próprio modo pelo qual se devem produzir e modificar as normas.

Há a necessidade de uma opção política que envolve a decisão sobre os mecanismos admitidos como válidos para "criar" o Direito; questão de grande repercussão para o Direito do Trabalho, pois este é um ramo do Direito que se caracteriza justamente pela sua pluralidade de fontes "formais"

Conforme lição de Miguel Reale, as fontes do Direito são estruturas normativas que implicam a existência de alguém dotado de um poder de decidir sobre o seu conteúdo, o que equivale a dizer um poder de optar entre várias vias normativas possiveis. $^{2}$

Desse modo, as fontes do Direito se diversificam em tantas modalidades ou tipos quantas são as formas do poder de decidir na experiência social.

Podem ser assim classificadas:

a. Legal: resultante do poder estatal de legislar, editando leis e seus corolários normativos;

b. Consuetudinária: expressão do poder social inerente à vida coletiva e revelada através de sucessivas e constantes formas de comportamento (poder decisório anônimo do povo);

c. Jurisdicional: que se vincula ao Poder Judiciário, expressando-se através de sentenças de vários graus e extensões;

d. Negocial: ligada ao poder que tem a vontade humana de instaurar vínculos reguladores do pactuado com outrem. ${ }^{3}$

Há um aspecto procedimental da fonte do Direito: uma norma jurídica precisa satisfazer ao conjunto de requisitos concernentes à sua elaboração. Somente têm vigência e são dotadas de validade objetiva as normas que obedeçam a esses requisitos, previstos pelo ordenamento jurídico de cada país para cada tipo de fonte. O conceito de fonte é inseparável da idéia de obrigatoriedade das normas por ela

2. Reale, Migucl. Fontes e Modelos de Direito: para um novo paradigma hermenêutico, São Paulo, Editora Saraiva, 1994, p. 11.

3. Idem, p. 13. 
enunciadas e essa obrigatoriedade inexistiria se não houvesse um poder (legislativo, costumeiro, judicial e negocial) capaz de instaurar vínculos de caráter coercitivo.

Se uma lei ou um contrato obrigam, cada um a seu modo e alcance, tal fato se dá justamente porque à fonte do Direito é inerente um poder de decidir, sem o qual não haveria norma vigente, ou seja, aquela posta com exclusão de qualquer outra.

2. O Pluralismo de Fontes do Direito do Trabalho

O Direito do Trabalho é um ramo do Direito que se caracteriza por admitir uma pluralidade de fontes de normas jurídicas ("fontes formais").

O pluralismo jurídico se manifesta pela diversificação dos processos de manifestação do Direito, de forma que um ordenamento possa admitir não-somente normas de origem estatal, mas também aquelas criadas pelos grupos sociais.

Conforme explica Amauri Mascaro Nascimento, ${ }^{4}$ segundo esta visão pluralista o Direito positivo se revela multiforme, na medida em que não se encerra com a Lei estatal: a esta se acrescenta a ação do grupo social particular, que dá origem a uma ordem jurídica própria, total ou parcialmente desvinculada do Estado, e em alguns casos até mesmo contrária à ordem jurídica estatal.

As fontes "formais" do Direito do Trabalho podem ser divididas em dois grandes grupos:

a. "heterônomas" (aquelas que produzem normas sem a participação direta dos sujeitos que a elas deverão se submeter); e

b. "autônomas" (aquelas que produzem normas com a participação dos sujeitos interessados que, portanto, autodisciplinam as suas relações jurídicas).

A idéia de que existem ordens jurídicas diversas dentro da sociedade é hoje admitida pela Ciência do Direito, pois o reconhecimento deste pluralismo - como demonstra Norberto Bobbios não significa negar a unidade do ordenamento jurídico como um todo, na medida em que este se compõe de normas superiores e inferiores, que se articulam dentro de uma estrutura hierárquica.

Dessa forma, não importa se uma determinada norma provém de fonte "autônoma" ou de "heterônoma", pois ela sempre fará parte de um ordenamento jurídico unitário, assumindo uma posição na hierarquia que este estabelece.

4. Nascimento, Amauri Mascaro. Curso de Direito do Trabalho. São Paulo, Editora Saraiva, 1987, pp. 126-127.

5. Bobbio, Norberto. Teoria dell'Ordinamento Giuridico (ob. cit.), pp. 25-67. 
O importante papel do pluralismo jurídico para o Direito do Trabalho é o de abrir o campo de produção das normas trabalhistas para os próprios entes sociais interessados, reconhecendo que a figura do "legislador" não é suficiente para regular as relações entre eles.

Isso representa a valorização da organização dos individuos em grupos, onde possam tratar da defesa de seus interesses comuns.

Certo é que, num sistema pluralista, podem surgir problemas de hierarquia, diante de eventual conflito entre as diversas normas jurídicas existentes. Assim, para o Direito em geral, entre normas de hierarquia diferente considera-se aplicável a de grau superior; entre as de igual hierarquia, prevalece a mais recente.

Mas para o Direito do Trabalho, essa matéria encontra solução diferenciada, por meio da aplicação do princípio da "norma mais favorável": no caso de conflito, entre normas oriundas de fontes de produção de diferente hierarquia, prevalece a que for mais favorável ao trabalhador, salvo disposição proibitiva de norma derivada de fonte superior.

3. Classificação das Fontes do Direito do Trabalho: Fontes Estatais, Não- Estatais e Internacionais

Para fins didáticos, pode-se efetuar uma classificação das fontes de Direito do Trabalho que leve em consideração apenas a origem das normas produzidas: se tratar de uma norma proveniente de um órgão componente da estrutura do Estado, a fonte é estatal; ao contrário, se provém do poder dos particulares ou de órgãos que não façam parte da estrutura do Estado, a fonte é não-estatal; por fim, se a norma tem sua origem nas Conferências da Organização Internacional do Trabalho ou em tratados celebrados entre Estados, a fonte é internacional.

\subsection{Fontes Estatais}

\subsubsection{A Constituição}

É a mais importante fonte formal de produção estatal do Direito do Trabalho.

A ampliação do objeto das constituições é um fenômeno que vem se verificando com o passar dos anos, a partir da constatação de que os fins e objetivos do Estado se incluem entre os elementos essenciais que o constituem. Com efeito, quanto mais se passou a discutir a finalidade do Estado, mais se ampliou o objeto das constituições. 
Em conseqüencia, há um constante e crescente processo de constitucionalização do Direito do Trabalho, que reflete a valorização obtida pelo trabalho dentro das sociedades contemporâneas: este passou a ser considerado como um dos fundamentos do Estado, o que trouxe como conseqüência a inclusão entre as normas constitucionais de diversas formas de garantia dos direitos dos trabalhadores.

Esse fenômeno é facilmente constatado pelo exame da Constituição brasileira, em especial o Capítulo II (Direitos Sociais) do Título II (Direitos e Garantias Fundamentais).

Trata-se de um aspecto que é valorado de modo positivo pela doutrina, tanto que Amauri Mascaro Nascimento, ${ }^{6}$ lembrando Paul Durand, afirma com propriedade que "a prática mostra que a constitucionalização do Direito do Trabalho garante mais completamente a liberdade social e provoca a sua evolução",

\subsubsection{A Lei}

É uma fonte "heterônoma" do Direito do Trabalho, visto que as regras nela contidas são produzidas pelo Poder Legislativo e não pela vontade própria dos entes sociais.

A produção da lei está reservada a um órgão externo à relação social (que é o Legislativo), segundo todo um processo adrede estabelecido e de acordo com os preceitos constitucionais de organização do Estado e dos poderes.

Ressalte-se que cada vez mais o processo legislativo vem se aprimorando para buscar refletir a "vontade" dos que serão atingidos pelas normas dele provenientes, por meio de debates com representantes da sociedade civil, audiências públicas, etc.

Mas é inegável que todo sistema político que se caracterize por um intervencionismo nas relações econômicas vale-se preferencialmente das leis como fontes do Direito do Trabalho.

O jurista italiano Renato Scognamiglio 7 afirma que as leis são (depois da Constituição) as principais fontes estatais do Direito do Trabalho e destaca o papel histórico que estas representaram na formação de tal ramo do Direito. No entanto, adverte que podem resultar inadequadas para a função reguladora em senso estrito do trabalho dependente, na medida em que os dados e problemas concretos propostos

6. Nascimcnto, Amauri Mascaro. Curso de Direito do Trabalho (ob. cit.), p. 144.

7. Scognamiglio, Renato. Diritto del Lavoro. Bari, Cacucci Editorc, 1987, pp. 273-274. 
nesta área são diferenciados, o que traz dificuldades para uma disciplina tecnicamente bem elaborada, pois esta se baseia sempre em uma caracterização tipológica das relações sociais.

Assim, acena com a necessidade de se buscar alternativas à ação da lei, sobretudo com o recurso às fontes extraestatais, que exprimem a vontade das categorias interessadas.

Estas colocações me parecem muito interessantes, pois demonstram a necessidade de se repensar o papel da lei como fonte do Direito do Trabalho.

Não há dúvida de que a lei continua a ser uma fonte importante; no entanto, é preciso ter em mente que as sociedades contemporâneas já admitem outros mecanismos que, sendo mais flexiveis, se mostram mais úteis para regular situações específicas.

\subsubsection{O Regulamento}

No Brasil, o Executivo desenvolve intensa atividade normativa, mediante os seus diferentes órgãos: decretos da Presidência da República, bem como portarias, circulares, resoluções e instruções normativas do Ministério do Trabalho, que regulamentam leis e se consubstanciam como fontes específicas do Direito do Trabalho.

Todas as normas contidas nesses tipos de instrumentos estão relacionadas com alguma lei, mas não são criadas pelo Parlamento e sim por órgãos técnicos, conforme regras de competência, possuindo bastante relevância, por exemplo, as de segurança e medicina do trabalho e de inspeção trabalhista.

\subsubsection{As Medidas Provisórias}

Normas que são elaboradas pelo Poder Executivo, mas que não têm o mesmo caráter do regulamento; ao contrário, possuem força de lei.

Previstas na Constituição brasileira (art. 62), podem ser adotadas pela Presidência da República em casos de relevância e urgência, gerando efeitos imediatos.

Trata-se de normas evidentemente anômalas, a partir da própria exigência de excepcionalidade. As graves conseqüências que podem advir de uma norma juridica estatal que tem efeitos imediatos (e que não é fruto de uma decisão amadurecida no Parlamento, mas sim de uma escolha de quem está à frente do Poder Executivo) não recomendam o uso freqüente de instrumentos como as "Medidas Provisórias"

No entanto, têm sido largamente utilizadas para regular questões trabalhistas, em matérias tão-variadas como o valor do salário mínimo, a participação 
nos lucros ou resultados das empresas e até mesmo a jornada de trabalho e o chamado "banco de horas"

\subsubsection{A Jurisprudência}

Dizer que "o juiz não cria Direito, mas simplesmente aplica aquele preexistente", significa negar todo um caráter criativo que está implícito nas suas funções.

O exemplo do papel criativo do juiz está na previsão - contida na generalidade dos ordenamentos jurídicos - da possibilidade de se utilizar a eqüidade para decidir determinadas questões, nos casos de lacunas da lei.

Ao proferir qualquer sentença, o juiz sempre estará criando Direito, pois - mesmo fora das hipóteses de lacunas da lei muitas vezes se mostra possível a utilização de um dispositivo legal em detrimento de outro, para solucionar uma situação concreta. Ou seja, trata-se de ato de criação "dentro da lei"

É clara a influência dos precedentes jurisprudenciais na definição do Direito: não se pode negar a repercussão das chamadas súmulas ou enunciados na atividade jurisdicional brasileira.

Embora inexista o efeito vinculante e o juiz seja livre para adotar a sua decisão (bastando fundamentá-la), a tendência é a de que venha a seguir as diretrizes fixadas nos precedentes, de tal forma que a sociedade os recebe como direito posto, criando a justa expectativa de que devam ser respeitados.

No processo do trabalho, a própria lei processual (art. 896, $\S 5^{\circ} \mathrm{CLT}$ ) autoriza o ministro do Tribunal Superior do Trabalho (TST) a denegar seguimento ao recurso, quando a decisão recorrida estiver em consonância com enunciado de súmula adotado por aquela Corte.

Além disso, ao julgar um dissídio coletivo, o juiz brasileiro não aplica Direito preexistente, mas sim cria as normas que deverão ser observadas nos contratos individuais de trabalho, no uso do poder normativo previsto no art. $114, \S 2^{\circ}$, da Constituição Federal.

\subsection{As Fontes Não-Estatais}

\subsubsection{A Contratação Coletiva}

Por meio de uma atividade de negociação os grupos sociais exercem o poder de auto-regulamentação, elaborando contratos coletivos, cujas cláusulas devem ser aplicadas às relações individuais de trabalho.

Os trabalhadores e os empregadores, organizados em suas respectivas 
associações, buscam a solução dos conflitos relativos ao trabalho na empresa valendose do processo de negociação coletiva.

A contratação coletiva, como fruto desse processo, significa então o contrato coletivo intensamente praticado, pois o sufixo "ão" é indicativo de ação intensa.

Aqui reside a grande vantagem sobre as fontes estatais do Direito do Trabalho: a contratação coletiva adapta-se melhor ao dinamismo do mundo do trabalho, um mundo onde as situações se modificam com muita rapidez, com repercussão direta nos interesses das coletividades.

O interesse coletivo é algo em constante mutação, justamente porque as necessidades de uma coletividade estão sempre sujeitas a variações, de acordo com o contexto social em que ela se insere.

O interesse coletivo é o interesse de uma pluralidade de pessoas a um bem que seja idôneo a satisfazer uma necessidade comum. Não se trata da soma de interesses individuais, mas sim da sua combinação, realizada de forma a compor uma totalidade indivisível: um interesse coletivo só pode ser satisfeito por um único bem, apto a atender às necessidades de toda a coletividade.

A contratação coletiva representa uma tendência contemporânea dos grupos a se dar sua própria lei; se a relação individual de trabalho se dá entre partes economicamente desiguais, aquela mais fraca deve compensar a sua condição utilizando-se do seu poder de união com os outros indivíduos que, compondo um grupo, estão em situação idêntica.

No Brasil, a contratação coletiva consubstancia-se fundamentalmente em dois tipos de instrumentos jurídicos: a. as convenções coletivas de trabalho (celebradas entre categorias profissionais e econômicas) ${ }^{8}$ ou b. os acordos coletivos de trabalho (firmados entre um sindicato profissional e uma ou mais empresas).

\subsubsection{O Regulamento de Empresa}

É o conjunto de normas que objetivam regular a organização técnica e disciplinar do trabalho em uma determinada empresa.

Sua origem é unilateral (quando elaborado unicamente pelo empregador e imposto aos trabalhadores, que não têm participação no seu processo de formação) ou bilateral (quando os trabalhadores participam da sua elaboração, discutindo as suas condições com o empregador).

\footnotetext{
8. Art. 611 da CLT.

9. $§ 1 "$ do art. 611 da CLT.
} 
O regulamento de empresa é tido como uma fonte do Direito do Trabalho na medida em que, ao buscar organizar a atividade produtiva, estabelece algumas condições que terão de ser observadas nos contratos individuais dos trabalhadores que prestam os seus serviços no âmbito empresarial.

No País é uma fonte de escassa utilização, porque facultativo: cabe às empresas a decisão sobre criar ou-não o seu regulamento, de forma que muitas delas não o fazem.

Mas não há dúvida que o regulamento de empresa pode ser um instrumento importante para a criação de normas jurídicas trabalhistas, se considerada a sua elaboração como uma forma de participação dos trabalhadores na gestão da empresa.

Com efeito, são diversos os ordenamentos que propugnam esta idéia, como expressão da democratização das relações de trabalho, dentro da organização empresarial. Com esse intuito, talvez fosse o caso de buscar incentivar a adoção do regulamento de empresa no Brasil.

\subsubsection{Os Usos e os Costumes}

São regras de conduta observadas de maneira uniforme e constante pelos membros de um determinado grupo social, que as consideram como juridicamente obrigatórias.

O costume é uma norma jurídica não-escrita, é o resultado da consciência coletiva de um grupo social; assim, um determinado comportamento humano se constitui em costume, quando é uniforme, geral e praticado com continuidade.

Simultaneamente convivem o elemento objetivo (prática de longa data) e o subjetivo (sentimento de que é obrigatório, "opinio necessitas").

Quando a lei se refere expressamente ao costume, este tem uma função de integração da norma escrita (é o chamado costume "secundum legem"); já quando a lei nada dispõe sobre determinadas matérias, a norma consuetudinária assume então uma função supletiva, preenchendo a lacuna do Direito escrito (costume "praeter legem"). Em princípio não se admite um costume que seja contrário a uma disposição legal ("contra legem").

Conforme ressalta Mozart Victor Russomano ${ }^{10}$ os usos e os costumes ainda têm relevância no Direito do Trabalho, mais do que nos demais ramos do Direito, 44.

10. Russomano, Mozart Victor. Comentários à CLT (v. I). Rio de Janciro, Editora Forensc, 1990, p. 
porque se trata de uma disciplina em constante transformação, onde os hábitos coletivos continuam a presidir a realização de muitos atos que lhe dizem respeito.

\subsubsection{O Contrato Individual de Trabalho}

$\mathrm{Na}$ grande generalidade dos casos, o trabalhador simplesmente adere às condições de trabalho impostas pelo empregador, inexistindo então uma atividade negocial capaz de gerar normas jurídicas.

Mas a própria lei (art. 444 da CLT) autoriza empregado e empregador a estipularem livremente as relações contratuais de trabalho, em tudo quanto não contravenha às disposições de proteção ao trabalho, aos contratos coletivos que lhes sejam aplicáveis e às decisões das autoridades competentes. Uma das partes pode até vir a se arrepender de uma cláusula assim convencionada, mas não poderá deixar de cumpri-la.

Condições especiais de trabalho, inseridas em contrato individual, não são comuns na realidade brasileira, mas podem ser encontradas em algumas situações específicas, como as de cargos de direção, de gerência, de confiança.

Pedro Vidal Neto, citando Ferrucio Pergolesi, assevera que a autonomia da vontade pode ser interpretada de dois modos diferentes: ou a vontade privada é autônoma e criadora de normas jurídicas, ou é subordinada à lei e opera como uma condição jurídica, um elemento dos fatos constitutivos de efeitos jurídicos.

Nessa visão, a autonomia privada autoriza os particulares a regular a própria conduta por meio do autocomando que é o contrato, nada lhe faltando para ser uma fonte normativa, pois "o contrato constitui uma relação jurídica, mas isto não impede que também a regulamente" "

\subsection{Fontes Internacionais}

As fontes "internacionais" do Direito do Trabalho são os tratados firmados entre dois ou mais Estados, bem como as convenções e recomendações emanadas da Organização Internacional do Trabalho (OIT), frutos das decisões tomadas em suas conferências.

Os tratados podem gerar normas trabalhistas, como se deu, por exemplo, com o instrumento celebrado entre Brasil e Paraguai para a construção da hidroelétrica

11. Vidal Ncto, Pedro. Do Poder Normativo da Justiça do Trabalho. São Paulo, Editora LTR, 1983, pp. 84-85. 
de Itaipu e que continha regras acerca da contratação de trabalhadores para a obra. Também o tratado que criou o Mercosul prevê a necessidade de harmonização das leis trabalhistas de cada um dos Estados signatários.

Registre-se que, de acordo com o art. 84, inciso VIII, da Constituição, o tratado é celebrado pelo presidente da República, mas precisa ser referendado pelo Congresso Nacional. Esse requisito não-inviabiliza a inclusão do tratado entre as fontes do Direito, pois é este que gera as normas jurídicas; a eficácia destas, no entanto, fica condicionada ao ato que deve ser praticado pelo Congresso.

Em relação às convenções e recomendações, muito já se discutiu se seriam ou-não fontes do Direito, na medida em que as regras nelas contidas não são imediatamente aplicáveis nos Estados-membros da OIT, pois precisam ser ratificadas, em conformidade com as previsões dos respectivos ordenamentos internos.

A necessidade desse "ato de recepção" leva Pedro Vidal Neto a afirmar que não as considera como fontes do Direito do Trabalho. ${ }^{12}$

É certo que os Estados não são obrigados a efetuar a ratificação das convenções e recomendações; no entanto, precisam necessariamente submetê-las aos órgãos competentes para a devida apreciação.

No caso do Brasil, por exemplo, as convenções da OIT precisam ser ratificadas pelo Congresso Nacional, o que se dá pela via do decreto-legislativo, instrumento que prescinde da promulgação pelo presidente da República, como bem lembra Cassio Mesquita Barros Júnior, acrescentando que "uma vez ratificadas têmo efeito de revogar as leis internas que eventualmente venham a contradizê-las". Dessa maneira, prossegue o professor, "as convenções ocupam forma peculiar de incorporação ao Direito interno; as não-ratificadas e as recomendações têm o mesmo valor da doutrina" 13

Sendo assim, não se pode negar a importância da ação da OIT para a criação do Direito do Trabalho: as suas convenções e recomendações são chamadas de "Direito Internacional do Trabalho", que é supraestatal, mas que sem dúvida representa um papel importante para as transformações dos ordenamentos de cada um dos Estadosmembros, sobretudo em função dos princípios que estabelece.

12. idem, pp. 85-86.

13. Barros Jr, Cassio Mcsquita. Perspectivas do Direito do Trabalho no Mcrcosul. São Paulo, 1993. Disscrtação (para o concurso de Professor Titular do Departamento de Dircito do Trabalho da FDUSP). pp. 276-277. 
Consoante, assinala Wagner Giglio, as convenções emanadas da OIT impõem certas obrigações aos Estados-membros, derivadas do simples fato de pertencerem àquela entidade supranacional: assim, todos os países que subscrevem uma convenção se obrigam a submetê-la, internamente, ao órgão ratificador, o que já constitui um efeito que independe da ratificação propriamente dita. E ainda - assevera o autor -, o Direito Internacional do Trabalho é parte integrante do Direito do Trabalho e tem como fonte precípua a convenção internacional. ${ }^{14}$

Arnaldo Sussekind afirma que as convenções e recomendações da OIT, uma vez ratificadas, constituem fontes formais de Direito, gerando direitos subjetivos individuais; já aquelas não-ratificadas constituem fonte material, pois servem de inspiração e modelo para a atividade legislativa nacional, os atos administrativos de natureza regulamentar, os instrumentos de negociação coletiva e a solução dos conflitos coletivos. $^{15}$

Assim, as convenções e recomendações da OIT devem ser consideradas fontes do Direito do Trabalho, de modo a assinalar o significativo fenômeno da formação material de um conjunto de princípios a ser submetido aos diversos Estados.

Exatamente por isso é que se afirma a existência de um Direito Internacional do Trabalho, cuja importância é ressaltada em face da globalização e da formação de comunidades econômicas (Mercosul, União Européia).

Essas fontes internacionais constituem então um ordenamento especial, supranacional, que só adquire validade no território de um Estado se este procede à ratificação dos respectivos textos, de acordo com as previsões contidas no seu próprio ordenamento interno.

Mas os princípios decorrentes dessas fontes internacionais podem ser considerados uma aspiração de unificação e integração internacional do Direito do Trabalho, medida oportuna diante da globalização da Economia.

São Paulo, março de 2001.

14. Giglio, Wagner. Fontes do Direito do Trabalho. Revista LTr, S.Paulo, v. 42, maio de 1978, pp. 570-572.

15. Sussckind, Arnaldo. Convenções da OIT São Paulo, Editora LTr, 1994, pp. 27-28. 